\title{
Sobre Caminhos, resistências e identidades: vivências e pesquisas que conectam Brasil e México.
}

\author{
About Caminhos, resistências e identidades: vivências e pesquisas que \\ conectam Brasil e México.
}

Filipe Asth; Maria Mostafa

Universidade do Estado do Rio de Janeiro

\section{RESUMO:}

Resenha de SIMÕES, G. L. et al (Orgs). Caminhos, resistências e identidades: vivências e pesquisas que conectam Brasil e México. $1^{\mathrm{a}}$ ed., Florianópolis: Papa-Livro, 2021.

\begin{abstract}
:
Review of SIMÕES, G. L. et al (Orgs). Caminhos, resistências e identidades: vivências e pesquisas que conectam Brasil e México. First ed., Florianópolis: Papa-Livro, 2021.
\end{abstract}

DOI: 10.12957/mnemosine.2021.61866

O livro Caminhos, resistências e identidades: vivências e pesquisas que conectam Brasil e México é uma viagem pelos percursos de pesquisadores brasileiros em estágio doutoral no México. São treze autores, de diferentes universidades, diferentes regiões do Brasil, com diferentes temas e olhares, que relatam suas vivências nesse estágio mais conhecido por todos como "doutorado sanduíche". Os autores nos apresentam universos feitos de camadas de Brasil e México, provocados por toda a riqueza que esse encontro produz. Frente a esses universos sutis, desenhados a partir dos contornos de cada pesquisador, seus anseios, implicações e ferramentas teóricas, com as aventuras de se fazer uma pesquisa em outro país, nos constituímos, de fato, como latino-americanos. São relatos cheios de cores, afetos, intensidades e sabores, como é o próprio México nos olhares encantados dos viajantes-pesquisadores.

A diversidade de concepções e temas vai nos guiando juntos por essa viagem ao México, orientada por um certo modo de "sentipensar" cada assunto abordado por meio de uma "escrita de vivências". O elo estabelecido entre os autores é o que nos permite acessar um universo constituído por afinidades que ultrapassam aquela experiência de 
pesquisa em outro país. O posicionamento que reafirma a importância da valorização de uma política comprometida com a internacionalização da educação, o cuidado ao pisar no terreno do chamado objeto pesquisado, o questionamento com relação a quem serviria a pesquisa e para qual propósito são algumas das pistas que apontam para o horizonte ético em que se constituíram as experiências narradas no livro.

O livro se torna uma leitura ainda mais especial por marcar um período imediatamente anterior à pandemia, nos provocando uma certa nostalgia, já que estamos em 2021, num momento em que viajar para fora do Brasil não nos parece uma possibilidade. A leitura nos convida a lembrar de um passado recente, de tempos em que os encontros eram presenciais, e sonhar com um futuro próximo em que a mobilidade internacional, de pesquisadores e de todos, possa ser retomada com segurança.

O livro é dividido em três partes, "caminhos", "resistências" e "identidades", e é seguindo essa organização que vamos conversar com cada um dos treze capítulosuniverso.

\section{Caminhos}

Na primeira parte, "caminhos", acompanhamos o percurso de quatro doutorandos em suas buscas por obras, documentos, funcionamentos e dinâmicas mexicanas que são parte das suas pesquisas.

O capítulo de abertura, "Quantos caminhos fazem o México? Apontamentos sobre um país de migrações”, de Alex Dias de Jesus, então doutorando (e hoje doutor) em geografia pela Universidade Federal da Grande Dourados, fala sobre a temática das migrações internas e externas no México, que marcam tão significativamente a história deste país. Jesus saiu do Mato Grosso do Sul, motivado a acompanhar o movimento migracional de haitianos que passaram pelo Brasil em direção aos Estados Unidos a partir de 2016. Com as dificuldades de entrada no território do "grande irmão", os grupos de haitianos acabaram por permanecer em cidades da fronteira norte mexicana. A partir desse objetivo inicial, o autor se deslocou por 12 estados no México e aprendeu sobre muitas outras migrações, para além dos haitianos: "De certa forma, os haitianos me ajudaram a entender não apenas a sua migração, mas as dinâmicas das migrações contemporâneas, com sucessivas entradas e saídas em territórios nacionais.” (p.15).

Jesus apresenta informações relevantes para entendermos a configuração de um país habitado por populações em trânsito, tanto de grupos da América Central quanto do 
próprio México, que desejam migrar para os Estados Unidos: “Olhar para fora e para o norte são comuns alternativas de reprodução da vida no México, assim como em outros países latino-americanos e caribenhos intensamente afetados pelo desenvolvimento desigual". (p.16) O cotidiano difícil dos migrantes que observou deu elementos para o autor concluir que não há nada de romântico nesses deslocamentos, pois muitas pessoas migram não para melhorar de vida, como se faz crer quando se pensa a partir de referências de grupos mais organizados economicamente, mas como um último e desesperado recurso para se manterem vivas, dadas as travas para os deslocamentos, a repressão violenta no processo de incorporação a novos territórios e o grau de exploração que aguarda a força de trabalho que busca refúgio. Jesus também conclui que, para os migrantes em trânsito, o caminho não é direto, como quem sai de um ponto A para um ponto B em linha reta. O caminho é tortuoso e nas curvas também se faz morada: "Para eles, entre a saída e a chegada, há um longo percurso que pode nunca terminar e os espaços de trânsito podem se converter em lugares de destino, mesmo que temporariamente". (p.22)

Dos caminhos das migrações passamos a acompanhar Vanessa Daniela de Moraes numa instigante busca por uma série de desenhos em "Procuram-se os cadernos de Francisco Toledo". Moraes, que pesquisa animalidade e escatologia na literatura e nas artes visuais, no doutorado em Comunicação pela Universidade de Brasília se interessou pelos Cuadernos de la mierda, desse que é tido como um dos mais importantes artistas contemporâneos do México, e tão pouco conhecido no Brasil. Sua busca começa na Cidade do México, onde os Cuadernos estariam, seguindo as informações disponíveis na internet. No entanto, a busca pelos originais não foi tão simples: as informações eram contraditórias e Moraes percorreu uma série de Museus, eventos e encontros na capital e em Oaxaca, cidade em que o artista residia no momento do seu estágio. Enfrentando diversos entraves burocráticos nas instituições responsáveis pela guarda das obras e conversando com pessoas próximas ao artista, ela foi formulando uma ideia da sua personalidade, e compreendeu que parte dessa dificuldade de acesso aos cadernos era reflexo da própria forma como Francisco Toledo lidava com sua persona pública. Moraes não se deu por vencida, e depois de percorrer diferentes caminhos a partir das pistas que ia descobrindo, conseguiu ter acesso a imagens dos cadernos, com boa resolução, ainda que com muitas restrições, como o compromisso de não reproduzir as imagens em lugar algum. 
Com as imagens em mãos, a pesquisadora embrenhou-se por Oaxaca para tentar, mesmo sabendo das dificuldades, uma entrevista com Toledo. Dividia seu tempo entre pesquisas no Instituto de Artes Gráficas de Oaxaca, conversando com os funcionários que a essa altura já a conheciam e davam todo tipo de dicas sobre horários em que ela teria mais sorte de encontrar o artista no Instituto - e conversas com moradores que tinham orgulho do cidadão oaxaquenho. Num desses encontros foi ajudada por um vendedor de doces, que foi com ela até a casa do artista para esperar ele passar: "A vontade que o artista saísse era mais dele do que minha, ele tinha uma vontade de me ajudar que me emocionava." (p.33). O senhor chegou a tocar o interfone da residência, mas mesmo assim não foram recebidos. Vanessa se encantou com toda a ajuda que recebeu dos oaxaquenhos. Depois disso, a pesquisadora se comunicou por diversas vezes com a assessora do artista, mas a entrevista não se concretizou. Ainda assim, colheu aprendizados de todos os caminhos percorridos: "Esgotei as possibilidades de um encontro e isso também me fez conhecer um pouco mais de Toledo, sua resistência para falar com as pessoas, seu passo apressado, seu ostracismo.”(p. 34) Depois de quatro meses do retorno da pesquisadora ao Brasil, Francisco Toledo faleceu, e veio a público que o artista estava já há um certo tempo lutando contra um câncer. Vanessa teve olhos sensíveis e faro aguçado para perceber Toledo onde ele não estava.

Do universo das artes somos convidados a pegar o caminho do judiciário mexicano, guiados pelo texto de Luma Poletti Dutra que, assim como Vanessa Daniela de Moraes, estava fazendo o sanduíche do Doutorado em Comunicação pela Universidade de Brasília. "Acesso à informação na Suprema Corte Mexicana” fala sobre as investidas da pesquisadora para fazer um estudo comparativo entre Brasil e México no tocante ao direito de acesso à informação pública. Somos informados, logo no começo do texto, que o México possui uma das Leis de Acesso à Informação (LAIs) mais avançadas do mundo, aprovada em 2002, servindo de referência para vários países da América Latina, inclusive para o Brasil, que aprovou a sua LAI em 2011. Por isso a ida ao México lhe pareceu muito apropriada. Dutra escolheu o Judiciário, pois entende que a pressão social por transparência recai mais sobre o executivo do que sobre o judiciário, cujas instituições são mais fechadas. E por isso, de acordo com a sua pesquisa, é nas instâncias do Poder Judiciário que é possível observar com mais precisão os impactos de uma política de acesso à informação. Seus lócus de pesquisa: o Supremo Tribunal Federal (STF) no Brasil, e a Suprema Corte de Justiça da Nação (SCJN) no México. Driblando 
desconfianças por parte dos funcionários da corte com que conseguiu contato, a pesquisadora conversou com ex-ministros da SCJN e servidores que tentavam mudar a imagem do Judiciário, diluindo a cultura do segredo e a consequente desconfiança da população sobre as atividades e os atores dos tribunais.

Também fazia parte do plano do seu plano de pesquisa entrevistar alguns acadêmicos, mas foi grande a decepção da pesquisadora com esse público: "Me interessava ouvir as análises de pesquisadores mexicanos que estudavam o tema do direito de acesso à informação e, contrariando minhas expectativas, foi o grupo mais difícil de acessar." (p.42) Levou muitos "nãos" e um pesquisador chegou ao ponto de não comparecer ao encontro agendado, não avisar e simplesmente nunca mais responder qualquer contato de Dutra. São atitudes que nos levam a pensar sobre o lugar da academia e sobre as concepções de pesquisa que habitam os próprios pesquisadores. Ao final do estágio a pandemia obrigou a pesquisadora a antecipar o retorno ao Brasil, mas o tempo de imersão nas instituições e universidades mexicanas foi essencial para que o estudo comparativo pudesse ser feito, já que grande parte dessa pesquisa não teria a mesma riqueza se fosse feita de forma remota.

Os caminhos da primeira seção do livro se encerram no texto de Hugo Bermalino de Morais, doutorando em Sociologia e Direito na Universidade Federal Fluminense: "Sentipensando os novos caminhos das águas partindo da reprodução ampliada da vida". Morais pesquisa os conflitos territoriais que emergem a partir da construção de grandes obras hídricas no Nordeste, com um estudo de caso na Paraíba. Foi a partir da discussão sobre a produção do comum na América Latina, pelo viés dos estudos comunitários e da produção da professora Raquel Gutiérrez, que o pesquisador considerou o estágio no México, estreitando os caminhos entre a Paraíba e a cidade de Puebla. No México, cursou disciplinas e seminários que ampliaram a gama das categorias sociológicas usadas da pesquisa, num ambiente plural de muitas trocas entre pesquisadores de diversos países da América Latina: “Aquele era um ambiente político e academicamente muito rico e pulsante, comprometido com as lutas sociais e com a renovação do pensamento crítico sob inovadoras bases epistêmicas e metodológicas" (p. 55).

O período em Puebla modificou a forma como o pesquisador analisou o material coletado em pesquisa de campo na Paraíba antes do período do sanduíche. Essa mudança se deve a duas categorias teórico-políticas que foram incorporadas pelo autor durante a experiência no México: a reprodução da vida em confronto com a reprodução do capital, 
e as lutas pelo comum. Essas novas categorias permitiram que o pesquisador pudesse entender e valorizar as formas de resistência cotidiana das populações afetadas pelas obras do Canal Acauã-Araçagi, na Paraiba. Nas palavras do autor, "O sanduíche foi, portanto, uma oportunidade ímpar para conhecer e aprofundar estudos acerca das lutas pelo comum na América Latina, com reflexões instigantes sobre os processos de resistência e luta em defesa das águas e dos territórios” (p. 55)

\section{Resistências}

Já na segunda parte, intitulada "Resistências", quatro pesquisadores se aventuram nas análises de experiências que se opunham às diferentes formas instituídas de poder e nos apontam, a partir de suas análises, que apesar dos fascismos em marcha e dos diversos mecanismos de assujeitamento, há outros modos de vida sendo inventados.

O cientista político colombiano Sebastián Granda Henao, mestre e doutor em Relações Internacionais e migrante no Brasil desde 2010, compartilhou sua experiência em "Andar perguntando pelos caminhos de Chiapas: compartilhamentos sentipensados sobre a autonomia zapatista". Sebastián faz um relato sobre sua ida para Chiapas a fim de procurar contatos e diálogos com as comunidades zapatistas em resistência, na busca de uma perspectiva sobre o que seria uma interpretação decolonizada da noção de 'segurança', mas revela que seu estudo sobre o problema da 'segurança' o fez perceber que há vida política para além das políticas de Estado e que elas acontecem em diversas formas de organização e de governo em um sentido mais amplo. $\mathrm{O}$ autor faz então uma análise do quanto a pesquisa que buscava o significado da noção de 'segurança' como categoria política se transformou em um aprendizado sobre autonomia como prática política e um possível caminho na desconstrução da matriz do poder moderno/ capitalista/ colonial/ heterocispatriarcal. O contato direto com as lutas concretas, lá onde elas acontecem, contribuiu para que sua análise sobre o objeto pesquisado nos permitisse pensar sobretudo na necessidade de uma academia engajada, que não produz nem alimenta a dicotomia entre aquilo que a gente pesquisa e aquilo que nos constitui.

Seguindo na mesma linha de análise, o doutorando em Ciências Sociais Gustavo Moura de Oliveira, em seu texto "Entre percursos e horizontes: ensinamentos das autonomias indígenas do México aos estudos sobre política”, chama a atenção para o fato de que temos sido impedidos de imaginar formas de vida diferentes da que o sistemamundo capitalista-colonial normalizou como única possível, e que, por isso, inúmeras 
experiências de organização de grupos sociais que não se centram no Estado são invisibilizadas por serem consideradas de baixo alcance. Sua intenção com a vivência no México, além da prévia investigação bibliográfica que já fazia parte da sua aposta metodológica, foi assinalar, de forma sistematizada, a capacidade da categoria autonomia para o que se chama de teorias da transição. Mas autonomia em relação a quê? - indaga o autor. "Autonomia em relação ao Estado? Em relação à dominação colonial? Em relação ao capital? Em relação à dominação patriarcal? Como antecipação da sociedade imaginada?” (p. 77). Esse foi o conjunto de questões, então, que o levou a querer se aproximar do processo de tipo revolucionário-libertário que acontecia nas montanhas de Chiapas, o Movimento Zapatista ou Neozapatista, cuja principal bandeira é a autonomia. A combinação dos estudos anteriores com a vivência no México lhe possibilitou utilizar a categoria autonomia como uma "poderosa lente analítica" (p. 79) sobre os diferentes modos de organização em nossa sociedade, assumindo "que se trata de um processo dialético (negar-construir-negar-construir-negar-construir infinitamente enquanto houver a forma-Estado atual) no qual as contradições do Estado - e, em alguns casos, do sistemamundo capitalista-colonial de forma ampla - são recorrentemente identificadas, expostas e mais ou menos superadas pelos movimentos, seja pela tática da transformação do Estado, seja pela de seu abandono" (p. 81).

Já Gabriel Lima Simões, autor de "Pensando a resistência a partir de outros modos de existência" e doutorando em Políticas Públicas e Formação Humana na Universidade do Estado do Rio de Janeiro, busca analisar a perspectiva das resistências populares, fazendo uma relação entre sua atuação como Analista de Gestão na Coordenação de Cooperação Social da Fundação Oswaldo Cruz (Fiocruz), seu contato direto com a favela, e sua vivência durante o período de doutoramento em outro país. É palpável a potência que essa experiência pode promover no desenvolvimento de sua pesquisa. Gabriel faz um relato primoroso e detalhado sobre algumas atividades que potencializaram a análise de seu objeto de pesquisa, seja por meio da participação em um curso diretamente relacionado ao seu tema de interesse, promovido pela professora que o acolheu na universidade do México, seja pelas visitas e viagens para diferentes regiões daquele país, nas quais ele pôde conhecer o cotidiano do seu povo e suas histórias de luta. Entre as possíveis articulações para sobreviver às políticas de opressão e controle biopolítico, o autor faz uma análise daquelas com que pôde entrar em contato direto na viagem a uma das sedes do Exército Zapatista de Libertação Nacional (que lhe permitiu aprofundar o 
conhecimento e se encantar pela história nos estudos realizados no curso que acompanhou por lá), da participação em um evento de celebração do 'dia internacional da língua materna' (a convite de uma brasileira que fazia sua pesquisa sobre esse tema) e da visita a uma famosa igreja que congrega a crença católica com crenças e rituais indígenas. $\mathrm{O}$ relato de sua experiência de encantamento com a resistência do povo mexicano nessas diferentes frentes foi permeado por um aspecto que o autor fez questão de frisar: a curiosidade e a abordagem nesses espaços com relação à sua deficiência física. Nesse ponto, seu relato nos incita, de um modo sutil, a pensar que de alguma maneira a simples presença do pesquisador em campo opera deslocamentos importantes no objeto pesquisado. Quem nos garante que não apenas o Gabriel, mas todos que se afetaram pelos encontros das pesquisas, também saíram encantados pela potência e diversidade de formas de resistência possíveis? Seu texto é uma provocação que também nos faz pensar sobre essa relação entre sujeito e objeto como um processo de construção no movimento do pesquisar.

E por falar em potência e diversidade de modos de resistência, a análise da arte como instrumento de luta aparece no capítulo "Fazer de outro modo: o Super-8 e as resistências estudantis de 1968", assinado pela doutora em Meios e Processos Audiovisuais pela Universidade de São Paulo (USP), Marina da Costa Campos, encerrando o segundo eixo do livro. A pesquisa desenvolvida por Marina no doutorado buscou traçar uma aproximação entre filmes experimentais realizados em Super-838 no Brasil e no México na década de 1970, cujo recorte foi a influência estética da contracultura e a abordagem crítica dessas obras aos regimes autoritários. A perspectiva de análise da sua pesquisa busca compreender as leituras que os filmes estudados efetuaram sobre as reverberações do ano de 1968 no México e no Brasil. O relato da sua vivência no México nos permite pensar sobretudo a respeito das políticas de memória existentes em ambos países. Além de um trabalho de revisão de documentações e filmes, a pesquisadora pôde participar de algumas atividades no momento em que o México organizava inúmeras homenagens aos mortos e desaparecidos do massacre de 2 de outubro de 1968 em Tlatelolco. Seu texto enfatiza que sua participação na realização dessas iniciativas mobilizadas para garantir a preservação da memória das lutas estudantis desse episódio a ajudou a entender como essas atividades foram importantes para reforçar um compromisso coletivo naquele país para que tragédias como aquela não se repitam mais. A dinâmica familiar desse marco histórico e as memórias das torturas, das mortes 
e dos desaparecidos políticos a levaram a uma inevitável comparação ao caso brasileiro, por conta do recrudescimento do regime militar a partir do mesmo ano de 1968. Mas “o que a arte podia fazer após aquela tragédia?” (p. 98) foi a questão colocada por um dos filmes investigados na sua tese. A potência da arte aparece então como uma ferramenta fundamental na afirmação de uma narrativa sobre esses períodos de muita repressão, tanto no Brasil, quanto no México, configurando-se em um importante instrumento de luta contra as opressões retratadas em seus objetos de estudo. O relato da sua experiência enquanto pesquisadora, no momento em que se rememorava esse marco histórico no México, foi fundamental, então, para reafirmar a necessidade de proteger uma memória coletiva.

\section{Identidades}

Na terceira e uma última parte do livro, cinco capítulos se agrupam sob a égide das "Identidades". Todos os cinco textos colocam em análise as identidades indígenas no México, traçando algum paralelo com o Brasil, ainda que por diferentes abordagens, questionamentos e vivências.

Na abertura dessa seção, Matheus Gonçalves França nos conta como foi a experiência de viver um casamento de novela mexicana, literalmente. Em “"La familia de la novia' relato da experiência como figurante em uma novela mexicana", acompanhamos o doutorando em Antropologia social da Universidade Federal de Goiás em uma produção da Televisa, grande rede de televisão mexicana responsável pela produção de grande parte das telenovelas que chamamos no Brasil de "novelas mexicanas", como as já clássicas do público brasileiro "A Usurpadora" e "Maria do Bairro". O convite para fazer a figuração surgiu de forma inesperada em meio ao trabalho de campo que França realizava na cidade de Oaxaca para pesquisar um gênero musical mexicano, de nome a banda ou tambora sinaloense. Em meio às pesquisas sobre a diversidade musical local, se manteve aberto para perceber as tensões das relações étnico-raciais e topou a aventura de participar do que seria um tradicional casamento oaxaquenho para a televisão.

$\mathrm{Na}$ trama da novela, seria encenado um casamento entre uma mulher de família rica de Oaxaca e um homem de família pobre, e os figurantes, que seriam os convidados do casamento, foram divididos entre convidados da noiva e convidados do noivo. França entendeu, por meio da conversa com outros figurantes e com a produção da novela, que as pessoas que estavam com trajes mais finos e que tinham aparência mais rica ficariam 
ao lado da noiva, enquanto o restante dos figurantes ficaria ao lado do noivo. Embora as tensões raciais fossem escamoteadas como uma questão exclusivamente de classe pelos outros figurantes e pela produção (pobres X ricos), França foi designado para a família da noiva também por ser branco, e observou ali o que chamou de “(...) uma valoração estética da branquitude" (p.114). Além disso, todas as atrizes e atores eram brancos, mesmo sendo uma novela que se passava em Oaxaca, uma das cidades com maior diversidade étnica do México. O racismo observado pelo antropólogo na experiência da novela contribui para o debate sobre racismos e branquitudes na América Latina, mas, mais do que isso, colocou em análise o próprio lugar pesquisador: “(...) também me forneceu um repertório simbólico, cultural e discursivo para cruzar minhas próprias experiências e a lente pela qual eu olho minhas referências culturais, em especial no que diz respeito às práticas racistas desde uma perspectiva de sujeito branco.” (p. 119)

O capítulo seguinte, de autoria de Ana Paula Cardoso Dornelles, doutora em Ciências da Comunicação pela Unisinos, é intitulado de "Um olhar sobre as publicidades e o consumo de cosméticos no México: identidades e alteridades”. Mobilizada pela falta de representatividade da beleza das mulheres da América Latina nas publicidades de cosméticos, a pesquisadora formulou seu problema de pesquisa a partir da pergunta “(...) como são construídas as identidades e estereótipos de beleza das publicidades femininas de cosméticos no Brasil e no México?” (p.122) A vivência na universidade mexicana, a UNAM, seja participando de seminários, disciplinas ou nas trocas do grupo de pesquisa que a recebeu, conferiu à pesquisadora uma visão mais ampla e precisa do mercado publicitário mexicano: patriarcal e machista, como o do Brasil. Em paralelo às atividades na universidade, Dornelles entrevistou algumas mulheres e chegou à conclusão de que não surpreende que as mexicanas não se sintam representadas pelas publicidades cosméticas, mas que essa falta de representatividade não é um impeditivo para o consumo. A discussão trazida pela pesquisa se relaciona com o capítulo anterior: as mexicanas não se veem nas publicidades de cosméticos e os mexicanos, de uma forma geral, parece que quase não se veem nas novelas que exportam para o mundo. No entanto, mesmo não representadas e pautadas pela publicidade na relação com seus corpos, e aqui entra o achado mais interessante e inspirador da pesquisa, as mexicanas ainda se mostraram orgulhosas do seu país, das suas identidades étnicas, da sua cultura e da sua beleza. São identidades construídas em meio à diferença, num enfrentamento constante “(...) 
superando o bombardeio midiático de outras culturas e modos de viver, assim como os estereótipos convidativos das publicidades transnacionais." (p.128).

Da discussão sobre a representatividade passamos a refletir sobre as línguas indígenas no capítulo “A sobrevivência da língua P'uerpecha e sua relação com hispanofalantes no estado de Michoacán" de Sônia Cristina Poltronieri Mendonça, Doutora em Letras pela Universidade Estadual do Oeste do Paraná. Com a intenção de fazer um estudo comparativo entre os Guarani de Tekoha Añetete (Brasil) e os P'uerpecha de San Isidro (México), a pesquisadora passou o período sanduíche entre a Cidade do México e a cidade de Los Reyes, onde a comunidade de San Isidro se localiza. Na capital, teve orientação com acadêmicos de longa trajetória na pesquisa das línguas indígenas e ficou muito tocada com a forma como foi recebida. Tudo isso colaborou para que a pesquisadora fizesse uma extensa pesquisa bibliográfica em diversas bibliotecas, aprofundando os estudos sobre multilinguismo. Na comunidade de San Isidro realizou entrevistas com informantes bilíngues de P'urhepecha e espanhol. Após as entrevistas e outras atividades como reuniões com lideranças comunitárias, apresentação dos resultados da parte brasileira da pesquisa e muita observação sobre os modos de vida e a cultura P'uerpecha, constatou que assim como é com os Guaranis, diversos costumes foram absorvidos pelas culturas analisadas, e que isso indica que essas identidades não estão estagnadas, estão vivas e seguem mudando, em conjunto com a manutenção das tradições. E é justamente esse processo que assegura a sobrevivência cultural e linguística destas comunidades. A experiência no México trouxe muitos ganhos para a pesquisa e para a pesquisadora, como podemos observar em todos os capítulos deste livro: "Não tenho dúvida de que este estágio doutoral proporcionou meu amadurecimento acadêmico e uma vivência cultural de valor extraordinário. Me senti uma pessoa melhor em todos os sentidos!” (p.141).

O livro encerra, então, com o desenvolvimento de dois capítulos que narram o contato de um engenheiro agrônomo e o de uma engenheira agrônoma, com diferentes experiências que compõem o universo da produção agrícola no México. O primeiro, "Entre pueblos e tianguis: os caminhos da transição agroecológica a partir de redes agroalimentares no México", é o capítulo no qual o professor e engenheiro Fábio Corbari, mestre e doutor em Desenvolvimento Rural Sustentável pela Universidade Estadual do Oeste do Paraná (UNIOESTE), narra um pouco da sua vivência com os mercados alternativos e agroecológicos. Seu desejo em aprofundar os estudos sobre os processos de transição agroecológica e compreender a mudança de práticas em direção aos sistemas 
alimentares sustentáveis em diferentes contextos e culturas foi o que o levou ao país considerado o berço da agroecologia e da revolução verde. E apesar do domínio do agronegócio e das corporações multinacionais nos processos produtivos no campo mexicano, o pesquisador traz à cena algumas experiências contra hegemônicas na tentativa de compreender os processos históricos que contribuíram para repensar as formas de fazer agricultura naquele país. Fabio afirma que algumas das iniciativas que se opõem à economia dominante ganharam notoriedade no México (através das lacunas deixadas pelo próprio sistema), usando sua estrutura para avançar como uma alternativa econômica justa. Entre essas iniciativas de unidades de produção familiar, de cooperativas autogeridas, de redes de produção comunitária, de organização de espaços de comercialização autogerido e de modos de produção orgânica com princípios agroecológicos, o autor narra com detalhes a sua imersão naquela com que avalia ter tido maior proximidade: os tianguis ("mercado" na língua Nahuatl). Para o pesquisador, os tianguis mexicanos se consolidam como espaços públicos de circulação de alimentos, mas também de bens, pessoas, culturas, sabores e saberes e por essa dinâmica característica são lócus de ação coletiva em que, além de um mecanismo de comercialização e geração de renda para os agricultores, se promovem a reprodução da identidade dos territórios, socialização e articulação política. Assim, seus estudos e sua imersão na cultura mexicana, modos de vida e experiências agroalimentares apontaram para a centralidade da questão cultural na transição agroecológica, cujas dimensões ambientais, sociais, ecológicas e culturais estão incorporadas em uma filosofia de vida inspirada nos povos originários e campesinos. Seu contato com a diversidade de experiências na produção agrícola mexicana contribuiu diretamente para o aprofundamento da análise da sua pesquisa doutoral, mas o compartilhamento dessa vivência nos ajuda sobretudo a "repensar as formas de consumo, de alimentação, de relações sociais e de atuação política" (p. 152-153).

Já o segundo relato, e último capítulo, é o da engenheira e educadora popular Marli Gondim de Araújo, mestre em Geografia Agrária e doutoranda em Geografia Agrária e Cultural. Em “A retomada da agricultura ancestral mexicana no sul do México: a milpa como eixo central e mobilizador da cultura indígena", a pesquisadora narra seu contato com os povos originários do sul do México, no qual buscou compreender como vem acontecendo a retomada da agricultura ancestral mesoamericana e o modo como incorporam a sacralidade e os rituais em momentos específicos de cultivos. A região 
escolhida, os municípios de Aldama, Tenejapa e Chenalló, no estado de Chiapas, se deu em função da avaliação de que os indígenas do sul tendem a manter as tradições. E uma dessas tradições, que se tornou objeto de sua análise na passagem pelo México, foi a milpa, um dos mais importantes fundamentos da agricultura indígena, que é o cultivo simultâneo de vários produtos em um mesmo terreno. Sua pesquisa, que buscou explorar o lugar estratégico e simbólico que a milpa ocupa não apenas no que se refere à importância de práticas agrícolas ancestrais, mas também na sua relação com o sagrado, permitiu entrar em contato com um sistema produtivo que se encontra vinculado também ao mito, à cosmovisão indígena, à medida do tempo e do ciclo da vida. A milpa, nesse sentido, cumpre um papel que engloba também aspectos de ordem cultural e as entrevistas realizadas pela pesquisadora puderam confirmar isso. Assim, Marli aborda a importância do movimento de retomada e de reencontro dessas culturas ancestrais mesoamericanas, especialmente após a crescente implementação que vinha ocorrendo desde a década de 80 no contexto da agricultura no México, de ações deliberadas de políticas neoliberais nesse setor, entre as quais se destacavam o desenfreado uso de agrotóxicos e o incremento dos monocultivos. Sua vivência com as práticas dos povos indígenas no México a levou a estabelecer comparações com os indígenas Xukuru do Ororubá, povos que habitam o agreste de seu estado de origem, Pernambuco, especialmente pela perspectiva de retomada de um modo de cultivo ancestral, e seu relato é primordial para nos lembrar “quantos conhecimentos podemos adquirir com os povos originários” (p. 163).

\section{Conclusão}

A riqueza dos relatos publicados nesta coletânea nos dá muitos elementos para reafirmar, junto com os autores, a importância desse contato com outra cultura, não apenas para o desenvolvimento de uma pesquisa e para a formação do estudante de pósgraduação, mas sobretudo para a ampliação da nossa sensibilidade para outros modos de vida possíveis, possibilitando a nossa própria reinvenção nesse processo. Nesse sentido, a experiência do trabalho de campo narrada em cada capítulo, da vivência em si de cada pesquisador, pôde nos mostrar o redirecionamento do rumo das pesquisas porque os encontros que se produziram nesse caminho já não possibilitaram que as pesquisas e nem os próprios pesquisadores fossem mais os mesmos. E a viagem ao México foi uma excelente oportunidade para experimentar essa provisoriedade das nossas verdades produzidas. 
Filipe Asth, doutorando em Políticas Públicas e Formação Humana (PPFH/UERJ)

E-mail: filipeasth@gmail.com

Maria Mostafa, doutoranda em Políticas Públicas e Formação Humana (PPFH/UERJ)

E-mail: mariamostafa@hotmail.com 